\title{
A tradução de termos culturalmente marcados em algumas obras de Jorge Amado para a língua inglesa
}

\author{
Laura de Almeida \\ Universidade Estadual de Santa Cruz (UESC), Ilhéus, Bahia, Brasil \\ prismaxe@gmail.com \\ Ivanir Azevedo Delvizio \\ Universidade Estadual Paulista "Júlio de Mesquita Filho" (UNESP) \\ Rosana, São Paulo, Brasil \\ ivanir@ rosana.unesp.br
}

DOI: http://dx.doi.org/10.21165/el.v45i2.698

\begin{abstract}
Resumo
Apresentamos uma análise dos termos culturalmente marcados na tradução de três obras de Jorge Amado para a língua inglesa. Baseamo-nos em estudos da tradução cultural assim como nos estudos culturais. Abordamos a questão da intraduzibilidade e da impossibilidade da tradução por Mounin (1975) e Ronái (1989), além da tradução cultural por Aubert $(1995,1998)$. Apoiamo-nos também nos estudos culturais de Fanon (1979), Hall (2002) e Bhabha (2007). Classificamos os termos coletados com base nos procedimentos técnicos da tradução categorizados por Vinay e Darbelnet (1960 apud CAMPOS, 1987). Constatamos que muitos dos termos selecionados se classificam como empréstimo e adaptação, o que ressalta uma relativa lacuna entre idiomas diferentes, que nem sempre têm o mesmo termo ao traduzirmos uma cultura por outra.
\end{abstract}

Palavras-chave: língua e cultura; identidade; tradução cultural.

The Translation of Culturally Marked Terms in Jorge Amado's books into English Language

\begin{abstract}
An analysis of culturally marked terms in the translation of three books by Jorge Amado into English language is presented. It is based on cultural translations studies and general cultural studies. Issues concerning untraduzibility and the impossibility of translation (according to Mounin (1975) and Ronái (1989), as well as those concerning cultural translation (according to Aubert $(1995,1998))$ were approached. The analysis is also based on cultural studies, according to Fanon (1979), Hall (2002) and Bhabha (2007). The collected terms were classified according to the translation procedures categorized by Vinay and Darbelnet (1960 apud CAMPOS, 1987). It was observed that many of the selected terms were classified as borrowing or adaptation, which highlights a relative gap among different languages that do not always have the same term when translating one culture into another one.
\end{abstract}

Keywords: language and culture; identity; cultural translation.

\section{Introdução}

Considerado um escritor mundialmente conhecido, traduzido para vários idiomas, Jorge Amado tem a questão cultural como uma de suas principais 
características, ou seja, o escritor apresenta vários aspectos socioculturais em seus romances, principalmente no tocante à sociedade baiana. No que diz respeito aos estudos realizados sobre a tradução cultural em obras de Jorge Amado, podemos considerar que:

Traduzir uma obra literária brasileira, como a de Jorge Amado para outra língua e cultura torna-se tarefa difícil para o tradutor, por mais experiente que seja, visto a dificuldade em se traduzir, em sua essência ou totalidade, a originalidade, a musicalidade, o gingado que alguns termos comportam, como por exemplo, a capoeira; o misticismo e o sincretismo religioso presente na equivalência dos orixás em relação aos santos católicos; o som dos instrumentos típicos utilizados nos terreiros, como o atabaque ou agogô; as iaôs em transe ao incorporar os orixás, suas vestes, trajes, comida, dança, festejos; o universo exótico e ao mesmo tempo místico que envolve a comida baiana, como o vatapá, o efó. (VALIDÓRIO; CAMARGO, 2005, p.2)

Como podemos constatar na citação acima, as autoras atentam para a dificuldade de se traduzir Jorge Amado devido ao retrato cultural que ele cria em suas obras, levando-nos aos seguintes questionamentos:

- É possível transportar elementos da cultura baiana para outra cultura sem perder o sentido?

- Quais ferramentas o tradutor pode utilizar a fim de resolver os problemas da intraduzibilidade de uma cultura para outra?

Para perscrutar essas questões, foi selecionado um conjunto de termos relacionados à cultura baiana extraído de três obras de Jorge Amado: Dona Flor e seus Dois Maridos (Dona Flor and Her Two Husbands); Tocaia Grande (Show Down) e Tereza Batista, Cansada de Guerra (Tereza Batista Home from the Wars), tendo como objetivos:

- Verificar as estratégias adotadas pelo tradutor da obra para a língua inglesa, em especial no que diz respeito à questão cultural, bem como em relação à forma como foi realizada a tradução de alguns itens característicos da cultura baiana;

- Discutir alguns resultados da análise descritiva e comparativa entre original e tradução para o inglês das obras de Jorge Amado selecionadas para nossa investigação; candomblé;

- Analisar as traduções de termos relativos à cultura baiana, especificamente ao

- Verificar o distanciamento/proximidade tradutório em relação aos termos na língua original e as tentativas de transferência de elementos culturais para a realidade linguística da língua traduzida.

O estudo teve como embasamento teórico as discussões em torno da tradução cultural e da intraduzibilidade (MOUNIN, 1975; RÓNAI, 1989; AUBERT, 1995). Para classificarmos as estratégias adotadas pelo tradutor, utilizamos a tipologia de procedimentos tradutórios apresentada por Vinay e Darbelnet (1960 apud CAMPOS, 1987, p. 46-55) e reformulada por Barbosa (1990). Para a análise da tradução dos elementos característicos da cultura baiana, buscamos os estudos realizados por Póvoas (1989, 2007), sobre o português falado do candomblé da Bahia, bem como as análises de Silva (1994) e Bastide (2001) e os estudos culturais de Fanon (1979), Hall (2002) e Bhabha (2007). 
Vale ressaltar que este trabalho não se propõe a apresentar soluções para as questões de incompatibilidade tradutória e sim verificar o que foi feito pelo tradutor para superar as dificuldades surgidas no percurso da tradução com relação aos elementos culturais.

\section{Tradução cultural e intraduzibilidade}

Os estudiosos da teoria da tradução têm salientado muito as diferenças culturais e de ambiente que são responsáveis pela ausência de determinadas noções e palavras que as designem ao se traduzir de uma língua para outra e que, em teoria, constituiriam desafios insuperáveis para o tradutor.

De acordo com Ronái (1989), por exemplo, existem palavras que, por mais que tentemos traduzi-las, recorrendo a todos os circunlóquios possíveis, chegamos à conclusão de só haver exprimido parte do seu conteúdo complexo. Tais palavras, em geral, acabam impondo-se sob sua forma original aos idiomas, que, na impossibilidade de forjarem seus equivalentes, incorporam-nas ao próprio vocabulário. Sendo assim, muitas vezes, sabendo-se de antemão que não existe equivalente perfeito, Ronái (1989, p. 4) observa que o tradutor nem tenta a tradução, resigna-se a manter o termo primitivo, valendo-se de recursos como o grifo, as aspas ou as notas de pé de página.

Essas palavras "intraduzíveis" nos remetem ao que Bhabha (2007, p. 230) chama de "estrangeiridade das línguas". Segundo esse autor:

A 'estrangeiridade' da língua é o núcleo do intraduzível que vai além da transferência do conteúdo entre textos ou práticas culturais. A transferência do significado nunca pode ser total entre sistemas de significados dentro deles, pois a linguagem da tradução envolve seu conteúdo como um manto real de amplas dobras... ela significa uma linguagem mais exaltada do que a sua própria e, portanto, continua inadequada para seu conteúdo, dominante e estrangeiro.

A esse respeito, Aubert (1995) observa que os planos estrutural, cultural e individual da linguagem são de naturezas diversas. Visto isso, ao abordar os problemas de se traduzir a cultura, Aubert (1995) argumenta que ela não pode ser resumida a uma simples transcodificação de léxico e gramática, uma vez que é marcada por conflitos, tensões e desequilibrios.

Assim, em relação à prática do traduzir, diante da limitação idiomática posta, o que é peculiar a uma língua não poderia, a rigor, ser plenamente traduzido.

Entretanto, Rónai (1989), tendo por base Mounin (1963), alega que essas diferenças linguísticas e culturais, essas tensões e conflitos não são obstáculos totalmente intransponíveis, conforme podemos apreciar no seguinte excerto:

Os que sustentam a impossibilidade teórica da tradução (entre eles, paradoxalmente, tradutores de real mérito) costumam alegar a intransponibilidade de certas virtudes próprias a cada língua. Metódico, o nosso autor [Mounin] disseca-lhes os argumentos um por um, demonstrando que nem a semântica, nem a morfologia, nem a fonética, nem a estilística peculiares a determinado idioma constituem obstáculos insuperáveis ao intérprete munido, além do conhecimento seguro das línguas, de cultura, intuição e bom gosto. (RONÁI, 1989, p. 31) 
No trecho acima, fica evidente o destaque dado ao papel do tradutor e à importância de seus conhecimentos linguístico e cultural sobre as línguas da qual e para qual traduz e do modo como os articula e equilibra.

Em relação à tradução da cultura e ao papel do tradutor, Aubert (1995) reconhece-lhe três posturas possíveis: a matricial, a assimilativa e a criativa, com especial inclinação para esta última. $\mathrm{Na}$ postura matricial, o referencial de toda a operação de traduzir concentra-se no texto e na língua/cultura do texto de partida. $\mathrm{Na}$ postura assimilativa, a perspectiva se inverte, com a substituição dos componentes linguístico-culturais do texto de partida por constituintes linguístico-culturais identificados com o espaço de recepção do texto traduzido. Na postura criativa, que em grande parte aproxima-se da assimilativa, o tradutor assume seu papel como coautor, sem conformar o seu fazer a um ou outro molde externo, seja o espaço de produção ou de recepção, vencendo o dever de obediência ao original e os receios de desagradar aos leitores, usando, a nosso ver, o que Ronái (1989) chama de "intuição e bom gosto".

$\mathrm{Na}$ postura matricial, predominam as modalidades de tradução direta, que proporcionam a manutenção no texto de chegada dos referentes culturais do texto de partida, tais como: empréstimo, decalque, tradução literal (palavra por palavra) e diversos recursos de explicitação (AUBERT, 1995). Na postura assimilativa, predominam as modalidades de tradução indireta, que têm como resultado $\mathrm{o}$ afastamento e, por vezes, apagamento dos referentes culturais da língua de chegada, que são diluídos, generalizados ou adaptados à língua e cultura de chegada, tais como a transposição, a modulação e a adaptação (AUBERT, 1995). É importante salientar que as posturas elencadas aqui não são excludentes entre si e que, de modo semelhante, o tradutor pode lançar mão de mais de uma modalidade ao traduzir um termo culturalmente marcado (tradução híbrida).

Diante de tantas possibilidades e posicionamentos, Ronái (1989, p. 10) pondera que, como não há equivalências absolutas, uma palavra, expressão ou frase do original podem ser frequentemente transportadas de duas maneiras, ou mais, sem que se possa dizer qual das duas é a melhor. Daí não existir uma única tradução ideal de determinado texto. Segundo o autor, haverá muitas traduções boas, mas não a tradução boa de um original.

Com base no exposto, observamos que a tradução deve ser vista como uma atividade subjetiva, reflexiva e criativa, cujo domínio da liberdade se estende entre os dois polos: a) o sentido do texto que se pretende traduzir e b) a língua para a qual se traduz.

Devido à particularidade deste trabalho, a essa discussão cabe acrescentar, ainda, outro ingrediente. Propomo-nos aqui a analisar como alguns termos que designam elementos culturais do candomblé foram traduzidos do Português para o Inglês em obras de Jorge Amado. O candomblé, consigne-se, é um culto religioso de origem africana, assim como a maioria dos termos utilizados para nomear os conceitos a ele relacionados. Sendo assim, a questão da tradução desse conjunto de termos passa, primeiramente, por seu processo de assimilação à própria língua portuguesa, fato que podemos observar no seguinte relato:

[...] No caso do contato do colonizador branco com os negros trazidos para o Brasil, o embate lingüístico [sic] determinou uma série de adaptações semânticas por parte do 
negro, na tentativa de se comunicar no novo contexto lingüístico [sic]. Assim, numa negociação, significantes portugueses passaram a ser utilizados com significados africanos e vice-versa. E quando essa transposição não podia ser feita, a forma lexical ficava de uso restrito a subgrupos. Por isso, enquanto o conceito de orixá foi tomado como santo, para o significado axé, não foi possível a tradução. (PÓVOAS, 2007, p. 228-229)

É importante relembrarmos que esse processo arraiga-se profundamente em questões de dominação e subjugação, inclusive a linguística, como nos faz ver o seguinte trecho de Fanon (1979, p. 9):

A violência colonial não tem somente o objetivo de garantir o respeito desses homens subjugados; procura desumanizá-los. Nada deve ser poupado para liquidar as suas tradições, para substituir a língua deles pela nossa, para destruir a sua cultura sem lhes dar a nossa; é preciso embrutecê-los pela fadiga.

Considerando que os termos abordados aqui se inserem no domínio do candomblé, cabe também colocar que os cultos religiosos afrobrasileiros, nos termos de Bastide (2001, p. 9), constituem "reduto privilegiado da resistência africana". Como reflexo dessa resistência, muitos termos usados no candomblé foram sendo incorporados à língua portuguesa e ganharam projeção, especialmente, por meio das obras de Jorge Amado e suas traduções. Cabe, neste trabalho, refletir sobre até que ponto algumas dessas traduções privilegiaram ou apagaram esses elementos culturais.

A seguir, apresentamos a metodologia adotada para detectarmos os trechos da tradução cultural referentes à cultura baiana e ao candomblé e analisarmos as estratégias adotadas pelo tradutor.

\section{Metodologia}

O desenvolvimento do presente trabalho realizou-se por meio de uma combinação de análises semimanuais e de análises computadorizadas. Inicialmente, em uma análise qualitativa, buscamos levantar as áreas semânticas consideradas preferenciais do autor. Entre as várias áreas semânticas encontradas em que a tradução cultural evidencia-se como algo quase que intransponível, observamos as seguintes: comida/bebida, religião/festejos/folclore, instrumentos musicais, superstições/crendices, expressões idiomáticas, gíria/palavrão, características das pessoas/do local.

Neste trabalho, particularmente, abordamos apenas o campo semântico da religião. Dessa forma, selecionamos termos voltados para o universo dos orixás, do terreiro, do pai de santo e de outros elementos concernentes ao candomblé. Vale ressaltar que foram selecionados apenas os termos coincidentes nas três obras por se tratar de um estudo comparativo. Embora as obras em questão não sejam permeadas de exemplos, nossa proposta foi examinar as poucas ocorrências e verificar a forma como se deu a sua tradução para a língua e cultura americana. Nosso percurso na coleta de dados foi com base na extração de trechos das obras redigidas em Português em que os termos citados ocorreram, bem como na busca dos excertos correspondentes nas obras traduzidas para o Inglês. 
Após a identificação dos termos culturalmente marcados e de suas traduções para a língua inglesa, as mesmas foram classificadas segundo a tipologia apresentada por Vinay e Darbelnet (1960 apud CAMPOS, 1987, p. 46-55) e reformulada por Barbosa (1990). Nessa tipologia, os procedimentos técnicos da tradução são ordenados segundo a dificuldade de execução pelo tradutor, ou seja, quanto mais próximos da língua original, mais fácil sua realização, sendo, assim, os primeiros - o empréstimo, o decalque e a tradução literal - no âmbito da tradução direta, e os demais - a transposição, a modulação, a equivalência e a adaptação - no âmbito da tradução oblíqua, que é a que, em busca do sentido, mais se afasta da forma do texto da língua original.

Vale ainda mencionarmos os processos de amplificação e condensação. Segundo Campos (1987, p. 43-47), diz-se que há "amplificação" quando a mesma coisa é dita na tradução com um número de palavras maior do que o do original. $\mathrm{O}$ procedimento contrário é o da "condensação", que consiste em dizer com um número menor de palavras da língua-meta o que na língua-fonte está dito com palavras em maior número.

Considerando as opções apresentadas pelo tradutor e baseados nos trabalhos que discorrem sobre as religiões afrobrasileiras, examinaremos as diferentes estratégias, procurando categorizar e analisar as traduções selecionadas. Para isso, tivemos por fio condutor da análise o seguinte pressuposto: ao traduzir de uma língua para outra, devemos traduzir não só a palavra em si como também o conteúdo cultural que a palavra traz.

\section{Análise comparativa entre as três obras}

Para iniciarmos a análise, organizamos um quadro com informações relativas às três obras analisadas com respeito à temática, existência de glossário e indicação do tradutor.

Quadro 1: Comparação entre Dona Flor, Tereza Batista e Tocaia Grande.

\begin{tabular}{l|c|c|c}
\hline $\begin{array}{l}\text { Parâmetros } \\
\text { comparativos }\end{array}$ & Dona Flor & Tereza Batista & Tocaia Grande \\
\hline $\begin{array}{l}\text { Temática: } \\
\text { Religiosidade, } \\
\text { elementos do } \\
\text { candomblé }\end{array}$ & Sim & Sim & Sim \\
\hline $\begin{array}{l}\text { Apresenta glossário } \\
\text { no final do livro } \\
\text { explicando os }\end{array}$ & $\begin{array}{c}\text { Sim, com explicação dos } \\
\text { termos em inglês } \\
\text { termos em inglês }\end{array}$ & $\begin{array}{c}\text { Sim, com explicação } \\
\text { dos termos em inglês } \\
\text { (p.551-553) }\end{array}$ & \\
\hline Tradutor (a) & Harriet de Onís (2001) & Barbara Shelby (1975) & Gregory Rabassa (1988) \\
\hline
\end{tabular}

As três obras têm em comum a temática da religiosidade. Em Dona Flor, a personagem tem ligação com o candomblé, frequentando o terreiro. Da mesma forma, em Tereza Batista, a protagonista também participa do candomblé. Em Tocaia Grande, não identificamos nenhum personagem em especial que participe do candomblé, embora os termos estejam presentes durante o enredo.

Em Dona Flor, o glossário é composto por sessenta e seis termos, dos quais vinte e oito são do candomblé, a saber: abebé, aku abo, afoxé, akikó, aku, aro ôke, atôtô, babalâ̂, caboclo, capoeira, candomblé, efó, epa hei, erukere, gri-gri, ibejes, 
inkice, iya moro, Korikoe Ulukotom, lasquiné, mokan, obá, odoia, ofá, ogan, ojojó, orixá, paxoro.

Em Tereza Batista, encontramos um glossário no final da obra, escrito em inglês, com vinte e cinco termos. Destes, cerca de quinze são referentes ao candomblé, a saber: axé, babalorixá, caboblo/a, candomblé, Exu Tiriri, iyalorixá, odóia, ogan, Ogum, Omolu, Orixá, Oxóssi, Oxum, Xangô, Iemanjá/Janaína/Inaê.

Em Tocaia Grande, existe a presença de termos do candomblé, mas não encontramos glossário e nem outra marca do tradutor, como nota de rodapé, ou qualquer intervenção a fim de explicar um termo cultural.

Nessas obras, encontramos onze termos coincidentes ligados ao universo do candomblé: candomblé, Ebó(s), Encantado, Orixá, Exu, Iansã, Omolu, Oxalá, Oxóssi, Xangô, Iemanjá.

$\mathrm{O}$ primeiro termo refere-se à designação do próprio culto (candomblé). $\mathrm{O}$ termo ebó, segundo Póvoas (2007, p.443), é o "conjunto de objetos que constituem uma oferenda, obrigação ou despacho."

Para Sangirardi (1988, p. 196) "encantado - s.m. Orixá, nos candomblés-decaboclo."

Orixá, por sua vez, é um "nome genérico das divindades dos negros nagôs que personificam as forças da Natureza, embaixadoras entre os homens e o Deus Supremo e encarregadas do equilibrio de todo o sistema cósmico. Anjo da guarda; encantado; invisível; santo." (PÓVOAS, 1989, p.182).

Os sete últimos termos referem-se aos nomes de diferentes orixás (Exu, Iansãa, Omolu, Oxalá, Oxóssi, Xangô, Iemanjá):

EXU. Mensageiro entre os humanos e os demais orixás. Sem Exu, nada se faz. Seus domínios são as encruzilhadas, onde ele está sempre pronto para levar recados e petições. Gosta de cachaça, farofa de azeite de dendê e de galo preto. Trocista, gozador e pregador de peças, seu gênio fez com que fiéis de outros credos imaginassem que ele é uma entidade demoníaca. Por isso, o culto aos orixás no Brasil também tem sofrido perseguições sem conta. Sua insígnia é o obé-fará, espécie de tridente de ferro. Suas cores são o vermelho e preto, e o dia de seu culto é a segunda-feira. (PÓVOAS, 2007, p.204)

IANSÃ. Também conhecida como OIÁ. Guerreira, destemida, senhora dos ventos, das tempestades, dos raios e da trovoada. É uma das esposas de Xangô. Comanda os astros, os ventos e os eguns, isto é, os espíritos dos mortos. De temperamento tempestuoso, todos temem a sua ira. Veste-se de vermelho vivo e carrega uma espada com a qual guerreia e comanda os raios. Inquieta e dada a todo tipo de mudanças, ela é o próprio Fogo em sua feição feminina. Seus filhos the oferecem acarajé, abará, cabras e galinhas vermelhas. Odeia abóbora e jaca-mole. Seu dia é quarta feira e é cultuada junto com Xangô. (PÓVOAS, 2007, p.208)

OMOLU. Orixá dono do mundo, médico dos pobres. (PÓVOAS, 1989, p.82).

OXALÁ. Orixá da paz e do amor, considerado pai da criação. Oxalá tem ojeriza às cores preto e vermelho. Não suporta sal, azeite de dendê e bebidas alcoólicas. Prefere pombos e igbin, espécie de caracol também conhecido por boi-de-oxalá. Seus devotos the ofertam grande quantidade de milho-branco cozido. Gosta do silêncio e da quietude. Não suporta vozerio, alarido, nem sujeira. Seu dia consagrado é a sexta-feira, quando os adeptos do candomblé, geralmente, passam o dia vestidos de branco. A ele, o povo-desanto dedica o mais profundo respeito e eterna reverência, pois o considera a luz do 
mundo. Em qualquer ritual dos terreiros, Oxalá é o último a ser saudado. Após sua palavra, nada mais pode ser dito. Tem duas manifestações: uma, de jovem guerreiro e outra, de velho alquebrado. Quando jovem, ele é OXAGUIÃ. Traja-se de branco ou prateado, carrega escudo, espada e uma mão de pilão. Quando velho, ele é OXALUFÃ. Traja-se de branco, dobrado ao meio, claudicante, apoiado em um longo cajado ritual, o paxorô. (PÓVOAS, 2007, p.210)

OXÓSSI. Orixá das matas, da caça e, por extensão, da busca, da procura, da pesquisa. (PÓVOAS, 1989, p.82)

XANGÔ. Orixá do raio, do trovão, da pedreira e da Justiça. (PÓVOAS, 1989, p.83)

IEMANJÁ. É a grande-mãe dos mares e oceanos. De seios fartos e acolhedores, é considerada mãe dos orixás e, portanto, dos homens também. Gosta de adornos femininos, flores e perfumes. Veste-se de azul-claro e branco ou prateado. Carrega em uma das mãos uma adaga curta e, na outra, um espelho, o abebé, símbolo de seu real poder. A ela são dedicadas festas públicas que congregam multidões em várias cidades costeiras do Brasil, quando the são oferecidas dezenas de balaios repletos de objetos do seu agrado. Seu dia preferido é o sábado. Gosta de galinhas e cabras brancas, ovelhas e patas. (PÓVOAS, 2007, p.209)

A seguir, apresentamos um quadro comparativo entre as três obras com base nos termos coincidentes entre elas e as modalidades da tradução utilizadas pelos tradutores de cada obra.

Quadro 2: Comparação entre os termos coincidentes no original e na tradução.

\begin{tabular}{|c|c|c|c|c|c|c|}
\hline Termo no & \multicolumn{2}{|l|}{ Dona Flor } & \multicolumn{2}{|c|}{ Tereza Batista } & \multicolumn{2}{|c|}{ Tocaia Grande } \\
\hline$* * * * * * * *$ & Inglês & Modalidade & Inglês & Modalidade & Inglês & Modalidade \\
\hline candomblé & candomblés & emprés timo & $\begin{array}{l}\text { voodoo } \\
\text { ceremonies }\end{array}$ & $\begin{array}{l}\text { adaptação+ } \\
\text { amplificação }\end{array}$ & candomblé & empréstimo \\
\hline Ebó(s) & // & omissão & $\begin{array}{l}\text { offering/ } \\
\text { voodoo spell }\end{array}$ & $\begin{array}{l}\text { adaptação/ } \\
\text { adaptação + } \\
\text { amplificação }\end{array}$ & Ebós & empréstimo \\
\hline Encantado & Deity & adaptação & $\begin{array}{l}\text { enchanted } \\
\text { spirits }\end{array}$ & $\begin{array}{l}\text { adaptação+ } \\
\text { amplificação }\end{array}$ & Gods & adaptação \\
\hline Orixá & Deity & adaptação & $\begin{array}{l}\text { Orixás } \\
\text { spirits }\end{array}$ & $\begin{array}{l}\text { emprés timo+ } \\
\text { adaptação+ } \\
\text { amplificação }\end{array}$ & Orixá & empréstimo \\
\hline Exu & Exu & emprés timo & Exu & emprés timo & Exu & emprés timo \\
\hline Iansã & Yansã & emprés timo & Yansã & emprés timo & Yana & emprés timo \\
\hline Omolu & Omolu & emprés timo & Omolu & empréstimo & Omolu & emprés timo \\
\hline Oxalá & Oxalá & emprés timo & Oxalá & emprés timo & Oxalá & emprés timo \\
\hline Oxóssi & Oxóssi & empréstimo & Oxóssi & emprés timo & Oxóssi & empréstimo \\
\hline Xangô & Xangô & empréstimo & Xangô & empréstimo & Xangô & emprés timo \\
\hline Iemanjá & Iemanjá & emprés timo & Iemanjá & empréstimo & Iemanjá & empréstimo \\
\hline
\end{tabular}

As principais modalidades observadas para a tradução dos termos estudados foram: o empréstimo (26), a adaptação (8), a amplificação (4) e a omissão (1), nessa ordem. Desses casos, alguns ocorreram de forma combinada: adaptação com amplificação (3) e empréstimo com adaptação e amplificação (1). 
Para melhor visualização e comparação das modalidades empregadas para a tradução desses termos, organizamos os dados no gráfico a seguir.

Gráfico 1. Comparação entre modalidades de tradução entre as três obras.

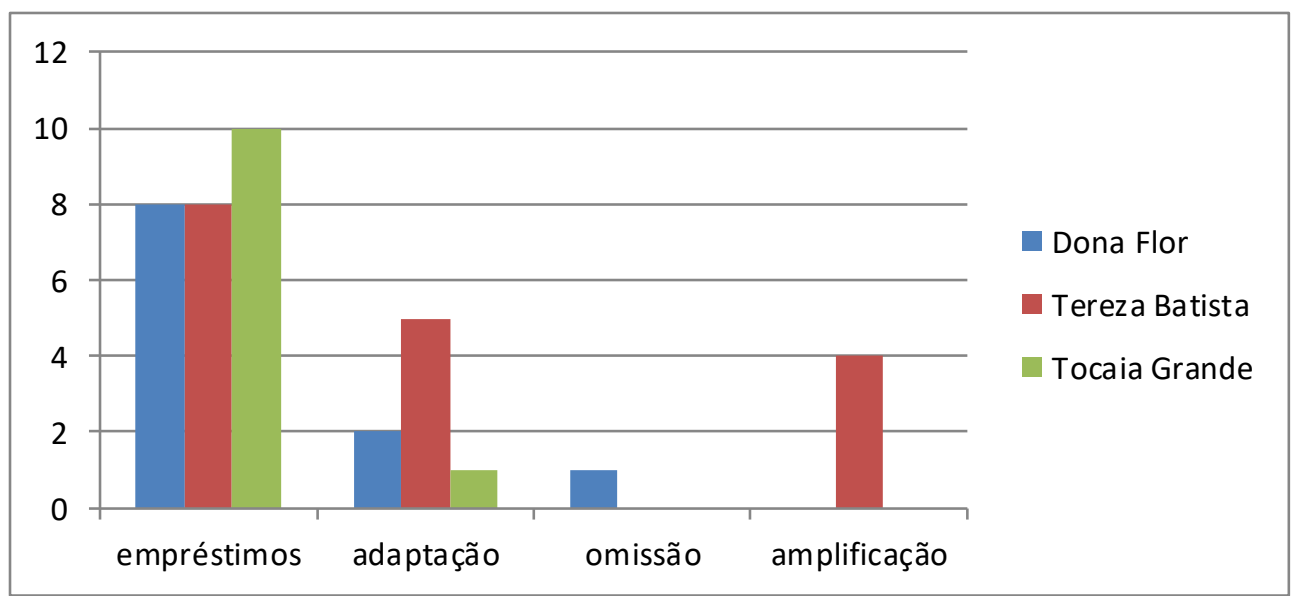

Podemos verificar que, em relação ao conjunto de termos sob análise, nas três obras predominou o uso de empréstimos.

Segundo Campos (1987, p.34-35), quando o tradutor se depara com alguma palavra ou expressão da língua-fonte que não tem correspondente ou equivalente na língua-meta, o recurso mais usual é transcrevê-la com todas as letras, ou com o que seria a pronúncia figurada delas: tem-se então um caso de empréstimo linguístico.

De fato, dos onze termos selecionados, sete foram traduzidos pelos três tradutores por meio de empréstimos, todos eles relacionados aos nomes dos orixás: Exu, Iansã, Omolu, Oxalá, Oxóssi, Xangô e Iemanjá.

A solução encontrada pelos três tradutores para esses termos, ou seja, o uso de empréstimos, vai ao encontro do que é colocado pelos estudos culturais, em especial o problema da diferença cultural:

[...] o sujeito da diferença cultural torna-se um problema que Walter Benjamin descreveu como a irresolução, ou liminaridade da 'tradução', o elemento de resistência no processo de transformação, 'aquele elemento em uma tradução que não se presta a ser traduzido'. (BHABHA, 2007, p.308)

A obra Tocaia Grande é a que apresenta o maior número de empréstimos (10), referentes aos sete orixás e aos termos candomblé, ebó e orixá. Na tradução de Dona Flor, além das designações dos orixás, também é usado o empréstimo candomblé. E na tradução de Tereza Batista, há o termo orixá traduzido como orixá spirits, uma combinação de empréstimo, adaptação e amplificação. Isso demonstra que grande parte dos termos referentes ao candomblé foi mantida em sua forma original.

Catford (1965 apud CAMPOS, 1987) e Vinay e Darbelnet (1972 apud CAMPOS, 1987) justificam o emprego do empréstimo ou por ser o item lexical em questão considerado intraduzível, ou pelo objetivo estilístico de dar "cor local" ao texto traduzido. 
Em relação à adaptação, Tereza Batista apresenta o maior número desse procedimento: candomblé (voodoo ceremonies), ebó (offering/voodoospell), encantado (enchanted spirits) e orixá (spirits). Em alguns desses casos, como podemos notar, no processo de adaptação houve também a amplificação, ou seja, a expressão do conceito por um número maior de palavras. Em seguida, vem Dona Flor, com as adaptações para: encantado (deity) e orixá (deity). Já em Tocaia Grande, temos apenas uma adaptação, para o termo encantado (Gods).

Quanto às opções de Tereza Batista, observamos que o tradutor usou o termo voodoo para compor a tradução de diferentes conceitos, como em candomblé (voodoo ceremonies) e ebó (voodoo spell). Segundo Silva (1994, p.140), o termo "vodu" é definido como "nome pelo qual são conhecidas as religiões de origem africana no Haiti. Popularmente designa feitiço, trabalho, magia feita para se obter o mal de alguém".

Outros estudos sobre o candomblé mostram a forma como esse tipo de prática religiosa é, muitas vezes, associado à "magia negra", como podemos constatar:

Os cultos afro-brasileiros, por serem religiões de transe, de sacrifício animal e de culto aos espíritos (portanto, distanciados do modelo oficial de religiosidade dominante em nossa sociedade), têm sido associados a certos estereótipos como "magia negra" (por apresentarem geralmente uma ética que não se baseia na visão dualista do bem e do mal estabelecida pelas religiões cristãs), superstições de gente ignorante, práticas diabólicas, etc. [...] (SILVA, 1994, p.13)

De fato, segundo Bastide (2001, p. 164):

É certo que existe na Bahia magia branca lado a lado com a magia negra. Magia de proteção contra doenças, desgraças ou morte, ao lado da magia ofensiva. Mas a magia branca tende a tomar a forma de amuletos ou de talismãs, como o uso da figa, o de orações católicas medievais escritas em pedacinhos de papel e suspensos ao pescoço, enquanto a magia negra tende a tomar a forma de Exu.

Sendo assim, traduções generalizadas por meio da palavra voodoo, como em voodoo ceremonies (candomblé) e voodoo spell (ebó), que associam o candomblé à magia negra, seriam reducionistas e parciais, visto não transmitirem a verdadeira essência e significado dos termos. O primeiro e terceiro tradutores preferiram usar o empréstimo candomblé. Em relação ao termo ebó, o terceiro tradutor também o utilizou na forma original, e o primeiro tradutor o omitiu.

Dos termos analisados, esse foi o único caso de omissão (ebó), feita pelo tradutor de Dona Flor. Como acabamos de citar, esse termo foi traduzido em Tereza Batista como offering ou também como voodoo spell. Em Tocaia Grande, recorreu-se ao uso do empréstimo ebó. 


\section{Consi derações finais}

O problema proposto neste artigo foi investigar as soluções encontradas pelos tradutores de três obras de Jorge Amado (Dona Flor, Tereza Batista e Tocaia Grande) a fim de lidar com a cultura e/ou com as palavras específicas relacionadas ao ambiente cultural, para as quais, teoricamente falando, não existiriam equivalentes possíveis na língua alvo. Para isso, aplicamos as modalidades de tradução (VINAY; DARBELNET, 1960 apud CAMPOS, 1987) para analisar um conjunto de termos relativos ao candomblé coincidentes nas três obras em questão.

Resumidamente, observamos que as modalidades usadas para a tradução do conjunto de termos culturalmente marcados foram: o empréstimo (25); a adaptação (4); a combinação de adaptação e amplificação (3); a combinação de empréstimo, adaptação e amplificação (1 caso) e a omissão (1 caso), considerando-se aqui cada tipo de combinação como uma modalidade.

Na tradução de Dona Flor, predominaram os empréstimos (8), seguidos de adaptação (2) e omissão (1), mostrando que o tradutor manteve-se bem próximo à língua e cultura de partida. Contudo, embora a obra contenha um glossário, verificamos que, dos onze termos selecionados, apenas dois estavam definidos no glossário: candomblé e orixá.

$\mathrm{Na}$ tradução de Tereza Batista, também predominaram os empréstimos (7), usados de forma isolada, e, além disso, destacou-se nessa obra o uso de adaptações: adaptação e amplificação (3); empréstimo, adaptação e amplificação (1) e adaptação (1), mostrando o esforço da tradutora em adaptar alguns conceitos para o universo da língua de chegada e torná-los compreensíveis nos moldes do leitor por meio da combinação de diferentes recursos. Nesta obra, dos onze termos estudados, seis constavam do glossário.

Na tradução de Tocaia Grande, houve o maior número de empréstimos (10) e um caso de adaptação. Contudo, embora o tradutor tenha se mantido próximo da língua de partida, usando os termos do candomblé em sua forma original, dando cor local ao texto, ele não disponibiliza glossário ou qualquer outro recurso que explique o significado desses termos e as particularidades culturais.

A nosso ver, são essas particularidades que fazem com que o leitor conheça, de fato, a cultura na qual o texto foi originalmente produzido. Foi com esse objetivo que este estudo pretendeu abordar a visão de mundo que o texto construído impõe ao leitor de uma obra traduzida. Em uma breve análise da tradução das obras originais para a língua inglesa, chegamos à conclusão de que o enredo em si é passado para o leitor da língua inglesa, porém, alguns elementos relacionados ao candomblé não são explicados de forma satisfatória e, algumas vezes, são apagados ou adaptados na tradução.

O uso do termo voodoo para se referir ao candomblé e a omissão do termo ebó, por exemplo, causam uma perda na tradução e, de certa forma, acabam empobrecendoa, pois não permitem que o leitor da língua inglesa conheça aspectos culturais específicos que são peculiares da obra de Jorge Amado. A omissão e a adaptação de termos culturalmente marcados da cultura baiana, como os do candomblé, pode ter relação ao que Hall (2002, p.49) chama de "sujeito fragmentado" ou então a criação de uma cultura homogênea ao "apagar" as diferenças existentes entre as línguas e generalizar uma ideia única para vários termos diferentes. 
Com base no exposto, consideramos que a questão cultural apresenta-se como um desafio na tradução de uma língua para outra. Embora a teoria discuta os limites da tradução, na prática, o tradutor pode fazer uso de soluções variadas a fim de tentar transpor as peculiaridades culturais, aproximando ou afastando-se dos referentes culturais da língua e cultura de partida em diferentes medidas.

\section{REFERÊNCIAS}

AMADO, J. Dona Flor e seus Dois Maridos. São Paulo: Martins, 1966. 535 p.

. Dona Flor and her two husbands. Tradução norte-americana de Harriet De Onís, H. Nova York: Alfred A. Knopf, 2006. 549 p.

. Teresa Batista cansada de guerra. São Paulo: Martins, 1972. 367 p.

. Teresa Batista home from the wars. Tradução de Barbara Shelby. Nova York: Alfred A. Knopf,1975. 549 p.

$485 \mathrm{p}$.

Tocaia Grande: a face obscura: romance. 11. ed. Rio de Janeiro: Record, 1998. $422 \mathrm{p}$.

Showdown. Tradução de Gregory Rabassa. Nova York: Bantam Book, 1988.

AUBERT, F. H. Desafios da tradução cultural. TradTerm, São Paulo, v.2, p. 31-44, 1995. 99-128, 1998.

Modalidades de tradução: teoria e resultados. TradTerm, São Paulo, v.5(1), p.

BARBOSA, H. G. Procedimentos técnicos da tradução: uma nova proposta. Campinas: Pontes, 1990. $120 \mathrm{p}$.

BASTIDE, R. O candomblé da Bahia: rito nagô. Tradução de Maria Isaura Pereira de Queiroz; revisão técnica de Reginaldo Prandi. Título original: Le candomblé de Bahia (rite nagô). São Paulo: Companhia das Letras, 2001. 379 p.

BHABHA, H. O Local da Cultura. Tradução de Myriam Ávila, Eliana Lourenço de Lima Reis e Glaucia Renate Gonçalves. Belo Horizonte: UFMG, 2007. 395 p.

CAMPOS, G. O que é tradução. 2. ed. São Paulo: Editora Brasiliense, 1987. 88 p.

FANON, F. Os condenados da terra. 2. ed. Rio de Janeiro: Civilização Brasileira, 1979. 275 p. (Perspectivas do homem. Série política; 42).

HALL, S. A identidade cultural na pós-modernidade. Tradução de Tomaz Tadeu da Silva e Guaracira Lopes Louro. 7. ed. Rio de Janeiro: DP\&A, 2002. 104 p.

MOUNIN, G. Os problemas teóricos da tradução. Tradução de Heloysa de Lima Dantas. Les problemes théoriques de La traduction. São Paulo: Cultrix; Paris, Gallimard, $1975.266 \mathrm{p}$.

PÓVOAS, R. C. A linguagem do candomblé: níveis sociolingüísticos de integração afro-portuguesa. Rio de Janeiro: José Olímpio, 1989. 193 p.

$\overline{2007.482} \mathrm{p}$.

. Da porteira para fora: mundo de preto em terra de branco. Ilhéus: Editus, 
RONAI, P. Escola de tradutores. Rio de janeiro: Nova Fronteira, 1989. 171 p.

SANGIRARDI JUNIOR. Deuses da África e do Brasil: candomblé \& umbanda. Rio de Janeiro: Civilização Brasileira, 1988. 206 p.

SILVA, V. Candomblé e Umbanda. Caminhos da devoção brasileira. São Paulo: Editora Ática, 1994. 149 p.

VALIDÓRIO, V. C.; CAMARGO, D. C. Um Estudo da Tradução de Termos Culturalmente Marcados em O Sumiço da Santa: The War of The Saints e Mar Morto: Sea of Death, de Jorge Amado, traduzidas por Gregory Rabassa. Estudos Linguísticos, XXXIV, p. 1349-1354, 2005.

Recebido em: 03/10/2015

Aprovado em: 30/05/2016 